\title{
Modelling of Mercury in the Arctic with the Danish Eulerian Hemispheric Model
}

\author{
J. H. Christensen, J. Brandt, L. M. Frohn, and H. Skov \\ National Environmental Research Institute, Frederiksborgvej 399, 4000 Roskilde, Denmark \\ Received: 19 December 2002 - Published in Atmos. Chem. Phys. Discuss.: 8 July 2003 \\ Revised: 21 October 2003 - Accepted: 8 September 2004 - Published: 22 November 2004
}

\begin{abstract}
A new 3-D mercury model has been developed within the Danish Arctic Monitoring and Assessment Programme (AMAP). The model is based on the Danish Eulerian Hemispheric Model, which in the original version has been used to study the transport of $\mathrm{SO}_{2}, \mathrm{SO}_{4}^{2-}$ and $\mathrm{Pb}$ into the Arctic. It was developed for sulphur in 1990 and in 1999 also lead was included. For the current study a chemical scheme for mercury has been included and the model is now applied to the mercury transport problem. Some experiments with the formulation of the mercury chemistry during the Polar Sunrise are carried out in order to investigate the observed depletion. Some of the main conclusions of the work described in this paper are that atmospheric transport of mercury is a very important pathway into the Arctic and that mercury depletion in the Arctic troposphere during the Polar Sunrise contributes considerably to the deposition of mercury in the Arctic.
\end{abstract}

\section{Introduction}

Mercury is a chemical component that has severe effects on humans and animals. It builds up in the food chain and the predators at the top of the food chain can accumulate rather large concentrations in their system. In the Arctic area very large concentrations of mercury have been measured in e.g. humans and polar bears. Therefore the monitoring of mercury concentrations as well as the mapping of sources of atmospheric mercury have become very important. In order to quantify the transport and deposition of mercury to the Arctic it is crucial to know the rate with which the mercury is transported from the air to the ground, i.e. the deposition rate. During the Arctic springtime a depletion in mercury concentrations in the air have been observed at several Arc-

Correspondence to: J. H. Christensen

(jc@dmu.dk) tic stations, including the Canadian monitoring station Alert. This depletion is quite strong as can be seen in Figs. 6-8. The period where the depletion is present corresponds to the period of the Polar Sunrise, and it has therefore been suggested that there must be a connection. A strong depletion is seen during the springtime, corresponding to the period of the Polar Sunrise (see also Schroeder et al., 1998; Lu et al., 2001).

The Danish Eulerian Hemispheric Model (DEHM) is a well documented and well performing 3-dimensional transport model, which have been validated on several other species than mercury (see e.g. Barrie et al., 2001, and Christensen, 1997). In the original version the model has been used to study the transport of $\mathrm{SO}_{2}, \mathrm{SO}_{4}^{2-}$ and $\mathrm{Pb}$ into the Arctic (see Christensen, 1997 and 1999). The simplified sulphur model system has been used in the first phase of the AMAP program (see Kämäri et al., 1998). The results with the $\mathrm{Pb}$ version were presented at the AMAP workshop on Techniques and Associated Uncertainties in Quantifying the Origin and Long-Range Transport of Toxic Chemicals to the Arctic, Bergen, Norway 14-16 June 1999 (see Christensen, 1999). Furthermore, a photochemical version including 60 species and more than 110 chemical reactions has been developed and validated (see Frohn et al., 2003). Also a $\mathrm{CO}_{2}$ version have been developed (Geels et al., 2004). For the current study a chemical scheme for mercury has been included, and the model is now applied to the mercury transport problem. Some experiments with the formulation of the mercury chemistry during the Polar Sunrise are carried out in order to investigate the observed depletion. 


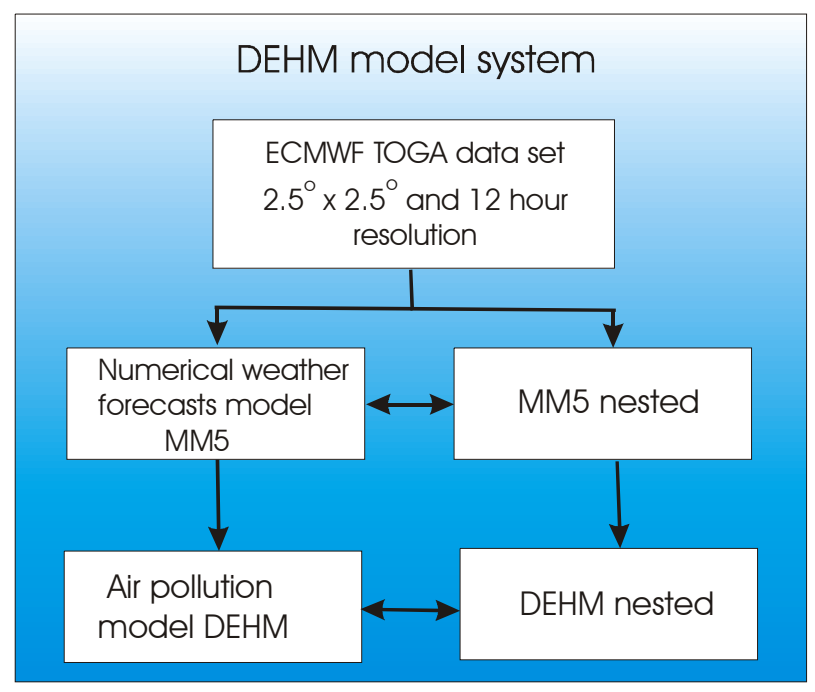

Fig. 1. Overview of the DEHM model system. Both the MM5 model and the DEHM model has nesting capabilities, and the MM5 model is initialised with data from ECMWF.

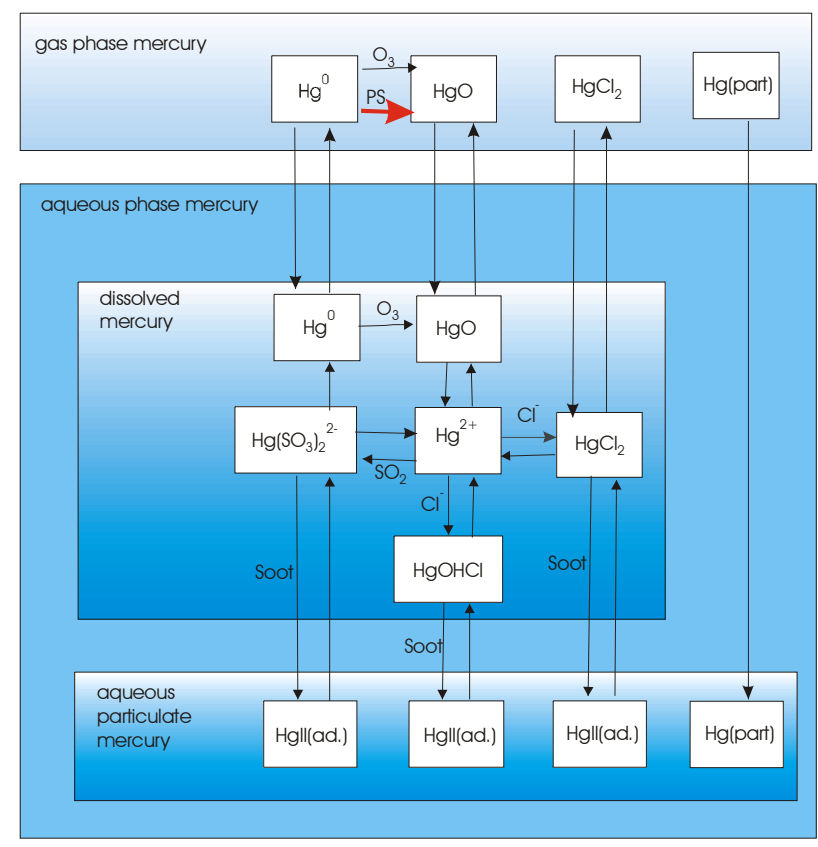

Fig. 2. The GKSS chemical scheme used in the mercury model (from Petersen et al., 1998). The red arrow shows the additional fast oxidation rate of $\mathrm{Hg}^{0}$ to $\mathrm{HgO}$ during Polar Sunrise (PS).

\section{Description of the DEHM model system}

The system consists of two parts: a meteorological part based on the PSU/NCAR Mesoscale Model version 5 (MM5) modelling system (see Grell et al., 1995) and an air pollution model part, the DEHM model, see Fig. 1.
The MM5 model produces the final meteorological input for the DEHM model. Global meteorological data, used as input to the MM5 mesoscale modelling system, are obtained from the European Centre for Medium-range Weather Forecasts $(E C M W F)$ on a $2.5^{\circ} \times 2.5^{\circ}$ grid with a time resolution of 12 hours. The MM5 modelling system includes two-way nesting capabilities, and it is therefore possible to perform meteorological model calculations over e.g. the Arctic Ocean or Greenland with higher resolution $(150 \mathrm{~km} \rightarrow 50 \mathrm{~km} \rightarrow 16.67 \mathrm{~km})$ with a nesting factor of e.g. 3 . Nearly 25 years of meteorological data from 1979 to 2003 are available and prepared for the system.

The hydrostatic version of the MM5 model is applied with the following choices of physical parameterisations:

- Mixed Phase (Reisner) explicit moisture scheme

- Betts-Miller cumulus scheme

- MRF boundary layer scheme with a 5 layer soil model

- Cloud-radiation scheme (Dudhia Scheme)

There are $97 \times 97$ horizontal grid points for the mother domain and $100 \times 100$ grid points for the nested domain. The resolution in the mother domain is $150 \mathrm{~km}$ and $50 \mathrm{~km}$ in the nested domain. There are 20 vertical layers with variable resolution in the model.

The DEHM model is based on a set of coupled full threedimensional advection-diffusion equations.

The horizontal mother domain of the DEHM model is defined on a regular $96 \times 96$ grid that covers most of the Northern Hemisphere with a grid resolution of $150 \mathrm{~km} \times 150 \mathrm{~km}$ at $60^{\circ} \mathrm{N}$. The nested domain for Europe is also defined on a regular 96x96 grid with a grid resolution of $50 \mathrm{~km} \times 50 \mathrm{~km}$ at $60^{\circ} \mathrm{N}$. The nested grid is a sub grid of the EMEP grid (see the web site of the Co-operative Programme for Monitoring and Evaluation of the Long-Range Transmission of Air Pollutants in Europe (EMEP) for details concerning the EMEP grid: http://www.emep.int/grid/griddescr.html). The vertical discretisation is defined on an irregular grid with 20 layers up to $\approx 15 \mathrm{~km}$.

The vertical diffusion is parameterised using a $\mathrm{K}_{z}$ profile for the surface layer based on the Monin-Obukhov similarity theory. This $\mathrm{K}_{z}$ profile is then extended to the whole boundary layer using a simple extrapolation procedure (see Christensen, 1997).

The advection is solved numerically using an Accurate Space Derivatives scheme with non-periodic boundary conditions (Frohn et al., 2002) for the horizontal advection and a finite elements scheme for the vertical advection. The diffusion is solved using the finite elements scheme. For further details on the numerical implementation see Christensen (1997) and Christensen (1993) as well as Frohn et al. (2002). 

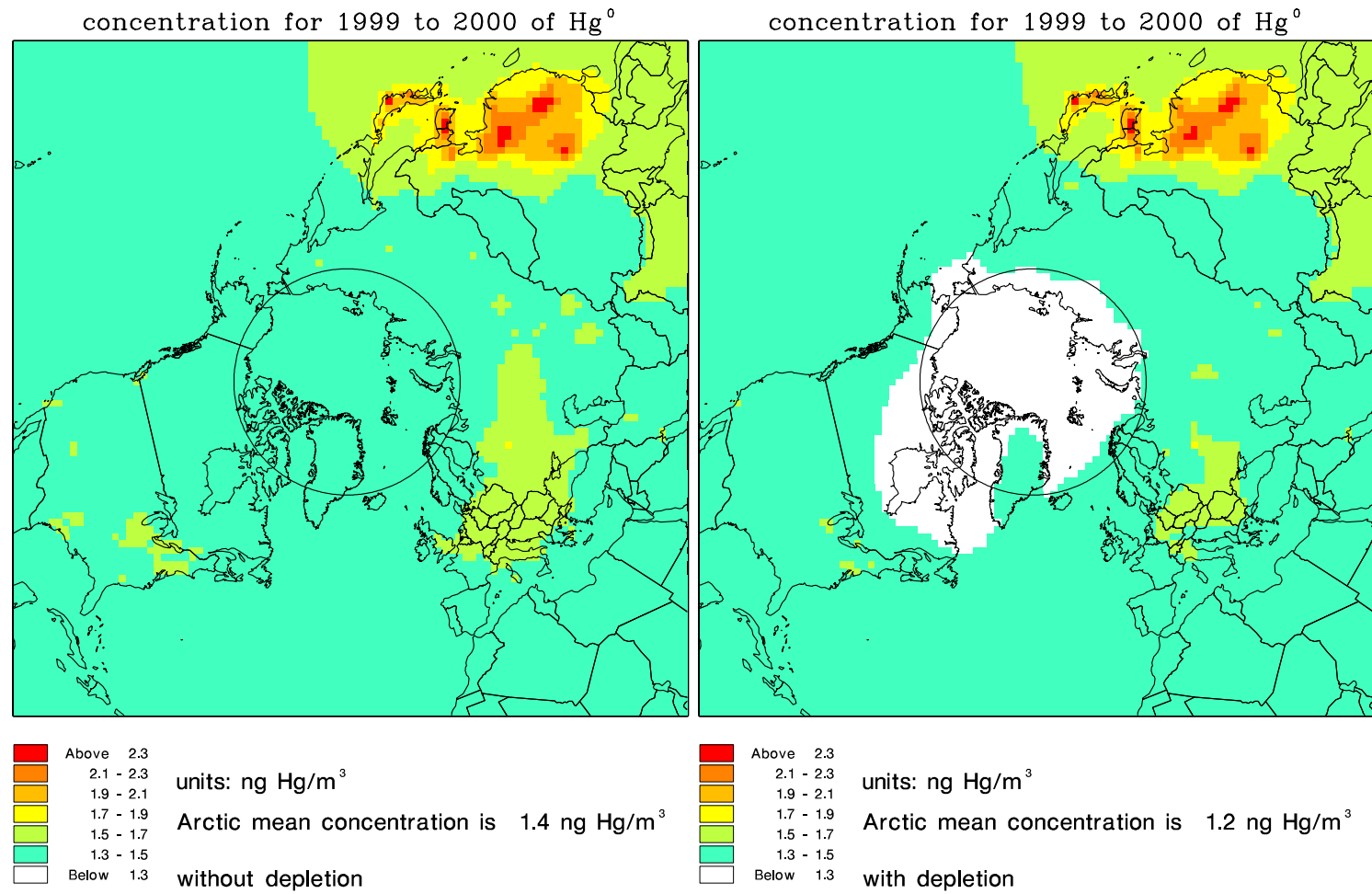

Fig. 3. The concentration of $\mathrm{Hg}^{0}$ in $\mathrm{ng} \mathrm{Hg} / \mathrm{m}^{3}$; without the fast oxidation rate causing Arctic mercury depletion (left) and with the fast oxidation rate (right).

\section{The mercury version of DEHM}

In the present mercury version of DEHM there are 13 mercury species, 3 in gas-phase $\left(\mathrm{Hg}^{0}, \mathrm{HgO}\right.$ and $\left.\mathrm{HgCl}_{2}\right), 9$ species in the aqueous phase and 1 in particulate phase.

The emissions of anthropogenic mercury are based on the new global inventory of mercury emissions for 1995 on a $1^{\circ} \times 1^{\circ}$ grid (Pacyna and Pacyna, 2002). This inventory includes emissions of $\mathrm{Hg}^{0}$, reactive gaseous mercury ( $\mathrm{RGM}=$ the sum of $\mathrm{HgCl}_{2}$ and $\mathrm{HgO}$ ) and particulate mercury. There are no re-emissions from land and oceans. However, a $\mathrm{Hg}^{0}$ background concentration of $1.5 \mathrm{ng} / \mathrm{m}^{3}$ is used as initial and boundary conditions.

The chemistry is based on the scheme obtained from the GKSS model, see Fig. 2 and Petersen et al. (1998). The mercury chemistry is depending on the concentrations of $\mathrm{O}_{3}$, $\mathrm{SO}_{2}, \mathrm{Cl}^{-}$and soot. Constant values of $\mathrm{Cl}^{-}$and soot concentrations are used, while $\mathrm{O}_{3}$ and $\mathrm{SO}_{2}$ concentrations are obtained from the photochemical version of DEHM. During the Polar Sunrise in the Arctic an additional fast oxidation rate of $\mathrm{Hg}^{0}$ to $\mathrm{HgO}$ is assumed in order to simulate the strong depletion: Inside the boundary layer over sea ice during sunny conditions it is assumed that there is an additional oxidation rate, which is added to the oxidation rate of elemental mercury due to the oxidation by ozone. This fast oxidation rate is depending on the sun angle ranging from no additional rate for a sun angle at $0^{\circ}$ to a maximum rate at $1 / 4 \mathrm{~h}^{-1}$, when the sun angle is higher than $20^{\circ}$. The fast oxidation stops, when the surface temperature exceeds $-4^{\circ} \mathrm{C}$ (based on experience from Pt. Barrow, Steve Brooks, pers. comm.). Information about sea-ice is obtained from the NCEP re-analysis, and this information is also used as input to the MM5 model system. The value of the maximum rate at $1 / 4 \mathrm{~h}^{-1}$ is based on model studies.

The dry deposition velocities of the reactive gaseous mercury species are based on the resistance method, where a surface resistance similar to the surface resistance for $\mathrm{HNO}_{3}$ obtained from the photochemical version of DEHM is used. The dry deposition velocity for particulate $\mathrm{Hg}$ is similar to the deposition velocity for sulfate (see Christensen, 1997). The wet deposition of reactive gaseous as well as particulate mercury is parameterized using a simple scavenging coefficients formulation with different in-cloud and below-cloud scavenging coefficients (see Christensen, 1997). The wet removal rates for all aqueous species are similar to the rates for sulfate. 

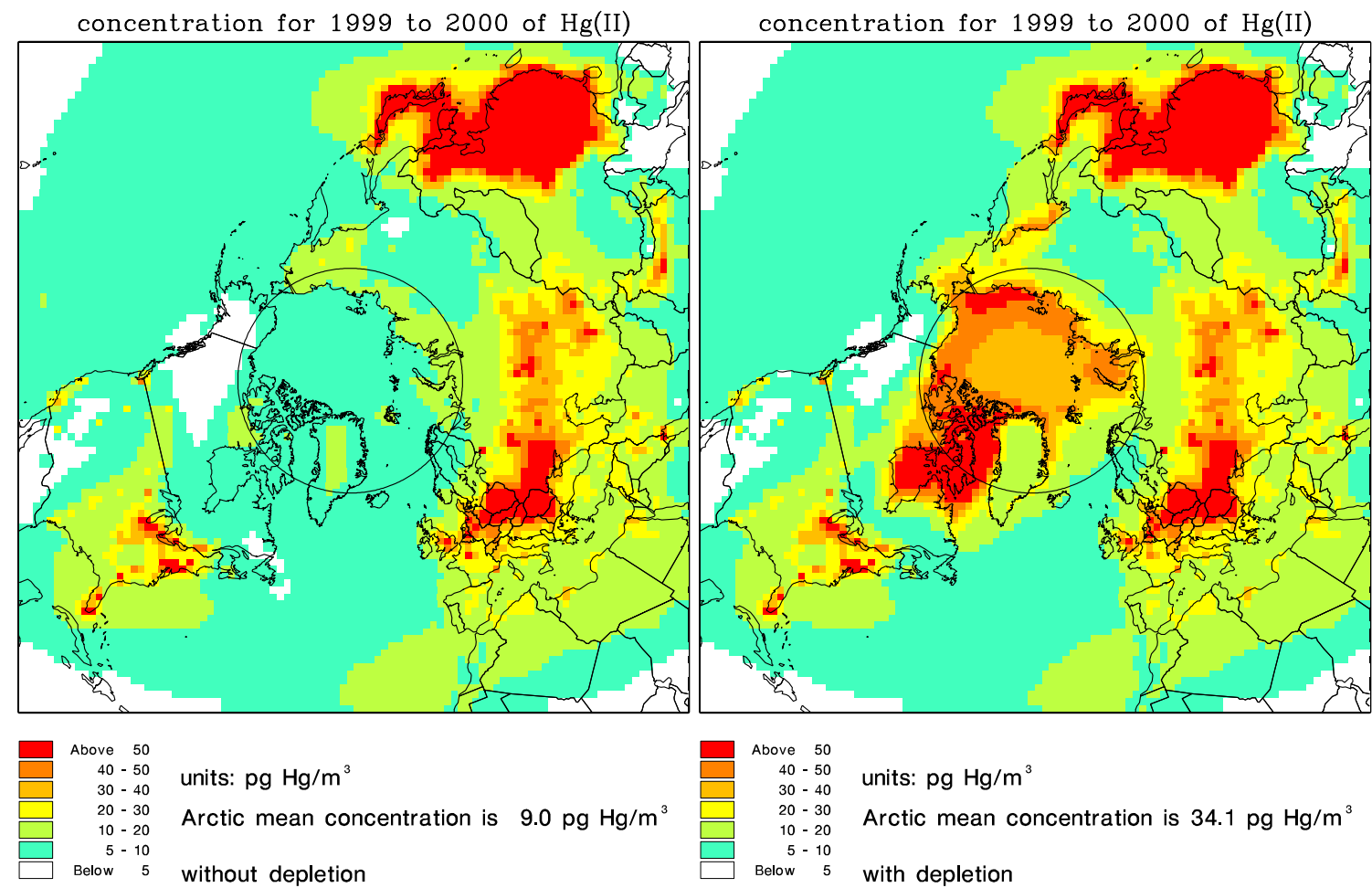

Fig. 4. The concentration of $\mathrm{RGM}(=\mathrm{Hg}(\mathrm{II}))$ in $\mathrm{pg} \mathrm{Hg} / \mathrm{m}^{3}$; without the fast oxidation rate causing Arctic mercury depletion (left) and with the fast oxidation rate (right).
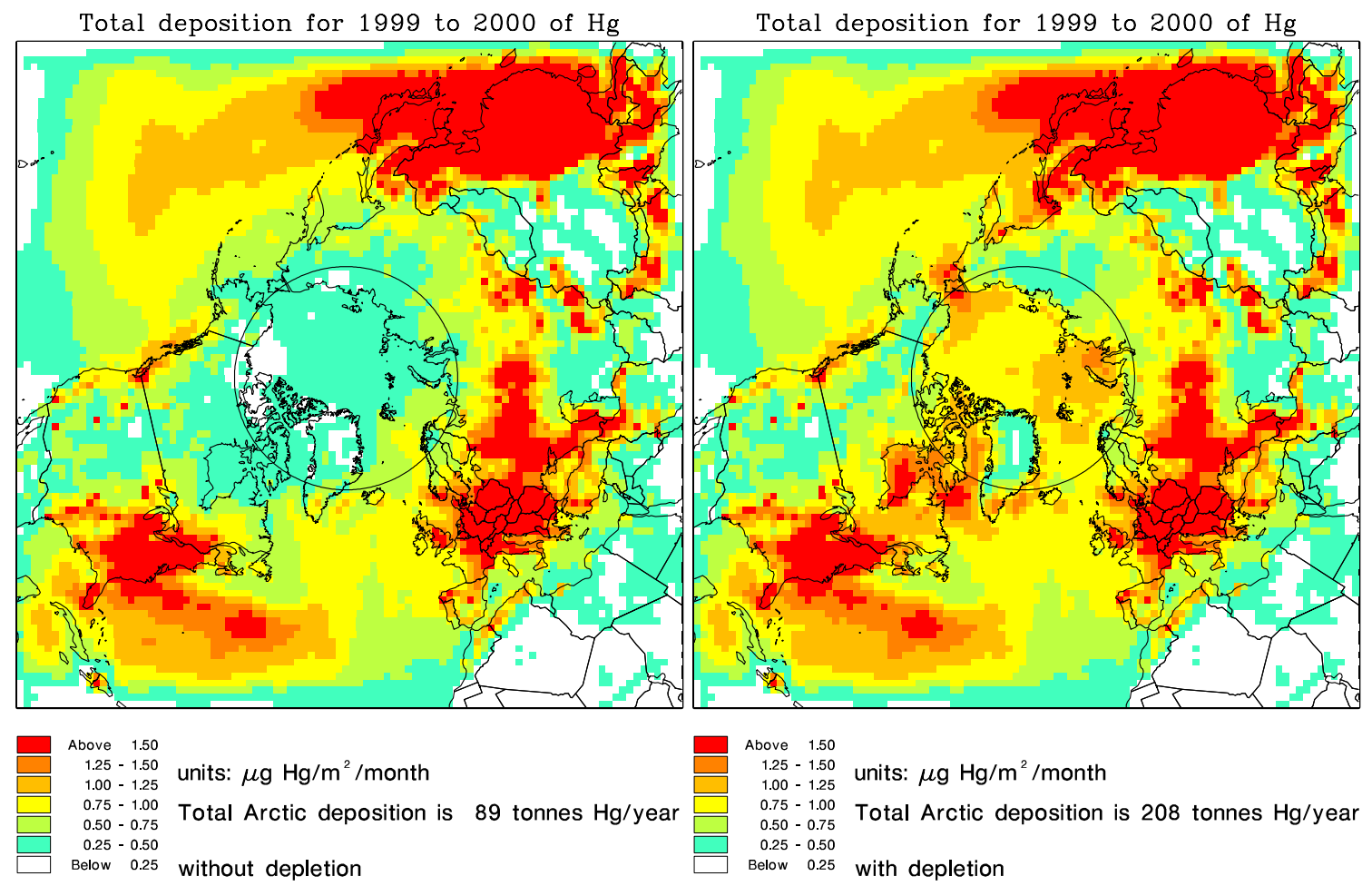

Fig. 5. The total deposition of mercury in $\mu \mathrm{g} \mathrm{Hg} / \mathrm{m}^{2} /$ month; without the fast oxidation rate causing Arctic mercury depletion (left) and with the fast oxidation rate (right). 

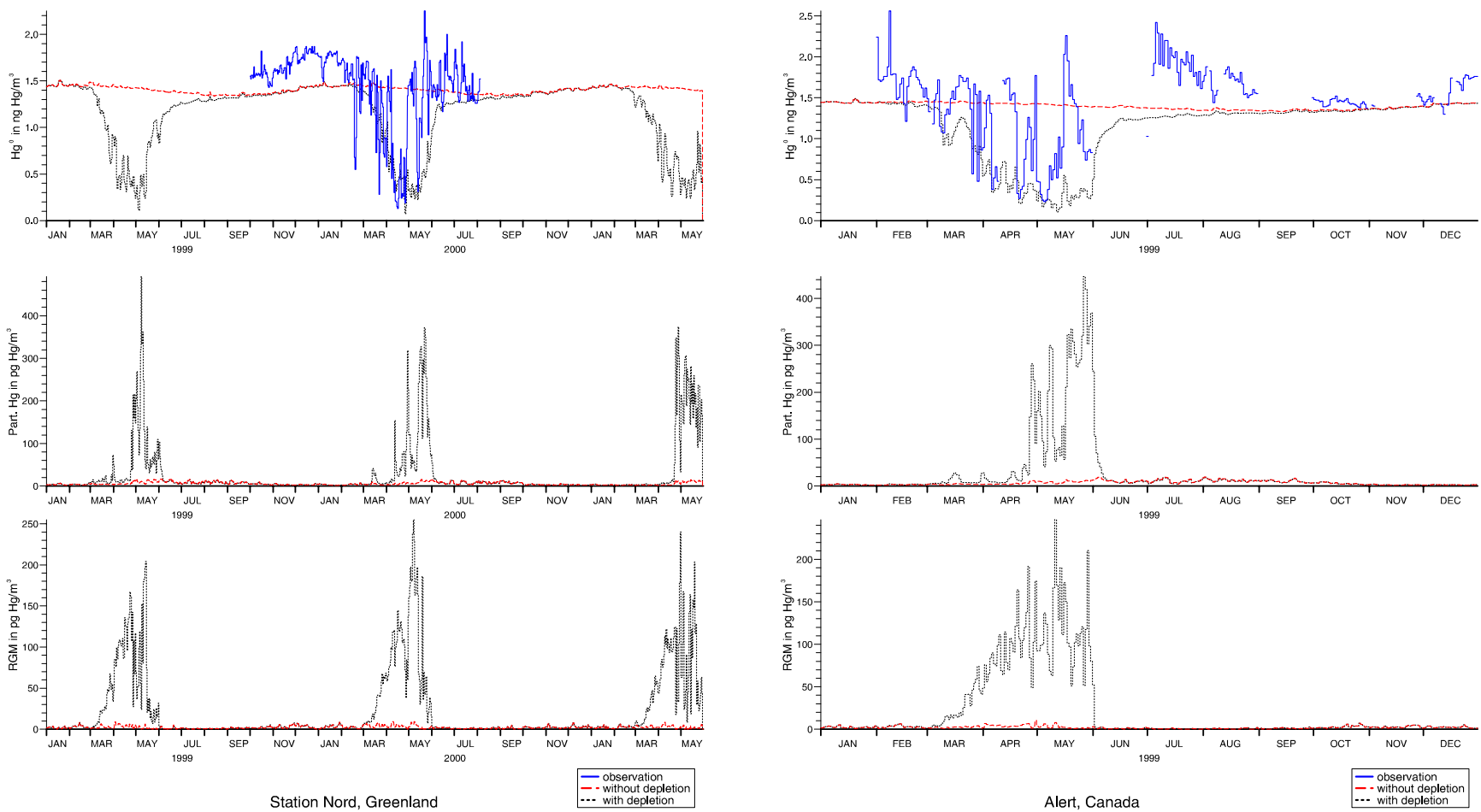

Fig. 6. Station Nord: Top panel shows a comparison of observed (blue curve) and calculated daily mean concentrations of $\mathrm{Hg}^{0}$ with two model versions; one without depletion (red) and one with depletion (black). Middle panel shows the calculated total particulate mercury and the bottom panel shows the calculated total reactive gaseous mercury.

\section{Results}

The mercury version of the DEHM model has been run for the mother domain for the period from October 1998 to December 2000. The mean concentration of $\mathrm{Hg}^{0}$ for two different runs, one without the fast oxidation rate causing Arctic mercury depletion and one with the fast oxidation rate are shown in Fig. 3. The highest levels of $\mathrm{Hg}^{0}$ are obtained in Asia, while the concentrations for Europe and North America is only slightly above the background level of $1.5 \mathrm{ng} \mathrm{Hg} / \mathrm{m}^{3}$. The depletion phenomena have large influence on the mean concentrations in the Arctic and only minor influence outside the Arctic.

The mean concentrations of Reactive Gaseous Mercury (RGM) are shown in Fig. 4 for the two different runs. For the run without depletion the highest levels are over emission areas in North America, Europe and Asia. For the model run with depletion, high concentrations of RGM are seen in the whole Arctic, especially over Hudson Bay and the near coastal areas over the Arctic Ocean.

The dry deposition velocity of RGM is very high and therefore the very high concentrations of RGM result in a dramatically increased deposition of mercury, which is

shown in Fig. 5. This example shows the importance of the Arctic mercury depletion for the total deposition of mercury in the Arctic area. The total deposition increases across the entire Arctic area as well as surrounding areas. According to the model runs performed in this study the total deposition of mercury increases from 89 to 208 tons pr. year for the area north of the Polar Circle due to the depletion.

For the Arctic areas the model results have been compared to measurements from Station Nord in North Eastern Greenland for the years 1999-2001, Alert in Canada for the year 1999 and Barrow in Alaska for the year 2000. The results show that there is quite good general agreement between calculated and observed concentrations of elemental mercury $\left(\mathrm{Hg}^{0}\right)$ for all three places (Figs. 6-8). Calculated concentrations of RGM as well as particulate mercury are also shown on the figures, and it can be seen that the levels of these species increase considerably during the depletion period. Measured concentrations of RGM at Barrow are shown on Fig. 8, and there again quite good general agreement is seen between the measured and calculated concentrations of RGM. An exception is the period from the middle of May to June, where the calculated concentrations of RGM are nearly zero, while the measured concentrations are high. The 

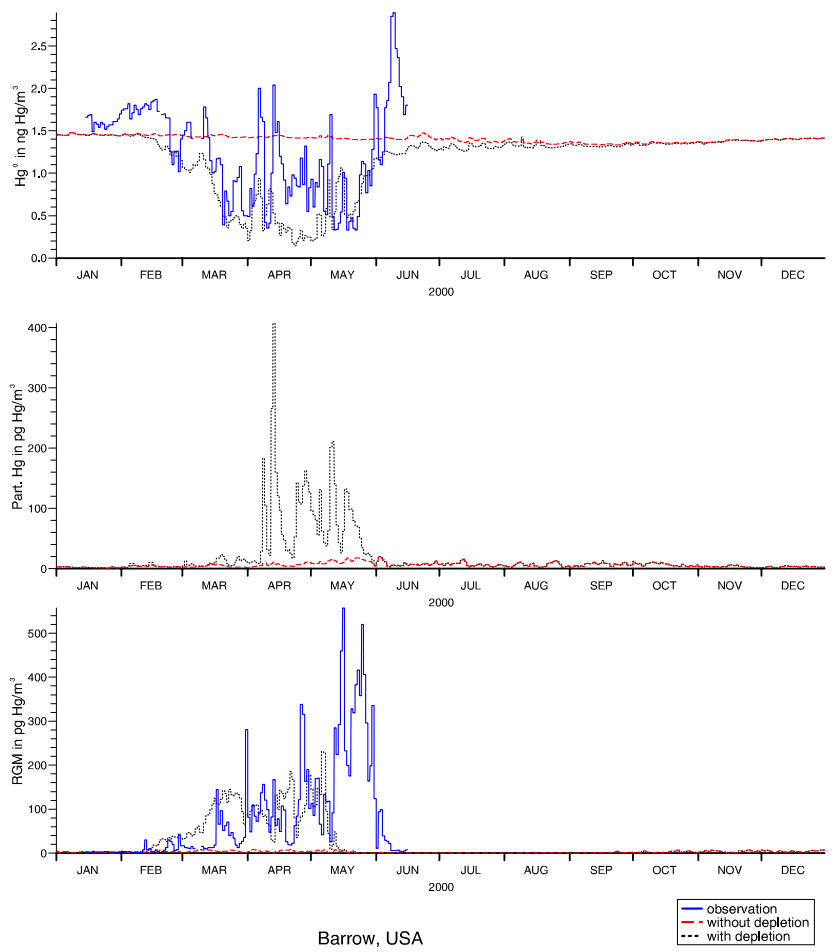

Fig. 8. Barrow, Alaska: Top panel shows a comparison of observed (blue curve) and calculated daily mean concentrations of $\mathrm{Hg}^{0}$ with two model versions; one without depletion (red) and one with depletion (black). Middle panel shows the calculated total particulate mercury and the bottom panel shows a comparison of observed (blue curve) and calculated total reactive gaseous mercury (black curve).

figures emphasise the importance of including the depletion process when calculating $\mathrm{Hg}$ concentrations and depositions in the Arctic areas.

\section{Conclusions and plans for the future}

A new hemispheric mercury model based on the Danish Eulerian Hemispheric Model System (DEHM) has been presented. The model system includes a meteorological model, MM5, and a three-dimensional air pollution model (DEHM). The chemistry is based on the scheme from the GKSS mercury model with some additional parameterizations of the very fast oxidation of $\mathrm{Hg}^{0}$ during the Polar Sunrise. The current version does not include re-emissions and natural emissions of mercury, which both are very important sources. Instead a concentration of $\mathrm{Hg}^{0}$ on $1.5 \mathrm{ng} / \mathrm{m}^{3}$ is used as initial and boundary conditions.

The model results for the Arctic have been compared with measurements in the Arctic, and there are reasonable agreements between observed and calculated concentrations. The model is able to reproduce the general patterns due to the depletion during the Polar Sunrise. The model has been used to make the first quantitative estimate of the importance of the mercury depletion in the Arctic troposphere during the Polar Sunrise for the deposition of mercury in the Arctic. The results from the model shows, that the total deposition of mercury increases with more than a factor 2 from 89 tonnes to 208 tonnes pr year for the area north of the Polar Circle.

Plans for the future work is:

- Continue the work with the parameterization of background chemistry, coupling with aqueous chemistry and other oxidation pathways of $\mathrm{Hg}^{0}$.

- Improve the parameterization of Arctic chemistry, coupling with GOME measurements of $\mathrm{BrO}$ (see Richter et al., 1998), coupling with measurements of mercury in the Arctic in order to understand the spatial and temporal distribution of the depletion.

- Coupling of mercury chemistry with a soot model.

- Re-emissions from oceans, sea-ice and landsurfaces.

- Further validation of the model system.

Acknowledgements. S. Brooks (Oak Ridge Associated Universities, USA) and S. Lindberg (Oak Ridge National Laboratory, USA) are acknowledged for the measurements from Barrow, Alaska. B. Schroeder (Environment Canada) is acknowledged for the measurements from Alert, Canada.

The model work is financially supported by the Danish Environmental Protection Agency with means from the MIKA/DANCEA funds for Environmental Support to the Arctic Region.

Edited by: M. Heimann

\section{References}

Barrie, L. A , Li, Y. , Lohmann, U. , Leaitch, W. R. , Kasibhatla, P., Roelofs, G.J., Wilson, J., McGovern, F., Benkovitz, C., Meliere, M. A., Law, K., Prospero, J., Kritz, M., Bergmann, D., Bridgeman, C., Chin, M., Christensen, J., Easter, R., Feichter, J., Jeuken, A., Kjellstrom, E., Koch, D., Land, C., Rasch, P: A comparison of large scale atmospheric sulphate aerosol models (cosam): overview and highlights, Tellus, 53B, 615-645, 2001.

Christensen, J.: Testing Advection schemes in a Three Dimensional Air Pollution Model, Mathl. Comput. Modelling, 18, 75-88, 1993.

Christensen, J.: Transport of Air Pollution in the Troposphere to the Arctic. PhD thesis. National Environmental Research Institute, DK-4000 Roskilde, Denmark, pp. 377, 1995.

Christensen, J.: The Danish Eulerian Hemispheric Model - a threedimensional air pollution model used for the Arctic, Atmos. Environ. 31, 4169-4191, 1997.

Christensen, J.: An overview of modelling the Arctic mass budget of metals and sulphur: Emphasis on source apportionment of atmospheric burden and deposition, in: Modelling and Sources: A Workshop on Techniques and Associated Uncertainties in Quantifying the Origin and Long-Range Transport of Contaminants to the Arctic. Report and extended abstracts of the workshop, Bergen, 14-16 June 1999, Annex 15, 1-5, 1999. 
Frohn, L. M., Christensen, J. H., and Brandt, J.: Development of a High-Resolution Nested Air Pollution Model - The Numerical Approach, J. Comput. Phys., 179, 1, 68-94, 2002.

Frohn, L. M., Christensen, J. H., Brandt, J., Geels, C., and Hansen K. M.: Validation of a 3-D hemispheric nested air pollution model, Atmos. Chem. Phys. Discuss., 3, 3543-3588, 2003,

\section{SRef-ID: 1680-7375/acpd/2003-3-3543}

Geels, C., Doney, S., Dargaville, R., Brandt, J., and Christensen, J. H.: Deconvolving the sources of synoptic variability in continuous atmospheric $\mathrm{CO}_{2}$ measurements over the Northern Hemisphere continents - a mesoscale model study, Tellus, 56B, 35-50, 2004.

Grell, G. A., Dudhia J., and Stauffer D. R.: A Description of the Fifth-Generation Penn State/NCAR Mesoscale Model (MM5), NCAR/TN-398+STR, NCAR Technical Note, June 1995, Mesoscale and Microscale Meteorology Division, National Center for Atmospheric Research, Boulder, Colorado, pp. 122, 1995.

Kämäri, J., Joki-Heiskala, P., Christensen, J., Degerman, E., Derome, J., Hoff, R., and Kähkönen, A.-M.: Acidifying Pollutants, Arctic Haze, and Acidifications in the Arctic, Chapter 9 in: AMAP Assesment Report: Arctic Pollution Issues. Arctic Monitoring and Assessment Programme (AMAP), edited by: Wilson, S., Murray, J., and Huntington, H., 621-659, 1998.
Lu, J. Y, Schroeder, W. H., Barrie, L. A., Steffen, A., Welch, H. E., Martin, K., Lockhart, W. L., Hunt, R. V., Boila, G., Richter, A.: Magnification of atmospheric mercury deposition to polar regions in springtime: the link to tropospheric ozone depletion chemistry, Geophys. Res. Lett., 28, 3219-3222, 2001.

Pacyna, E. G. and Pacyna, J. M.: Global emission of mercury from anthropogenic sources in 1995, Water, Air, and Soil Pollution, 137, 143-165, 2002.

Petersen, G., Munthe, J., Pleijel, K., Bloxam, R., and Vinod Kumar, A.: A comprehensive eulerian modeling framework for airborne mercury species: development and testing of the tropospheric chemistry module (TCM), Atmos. Environ. 32, 829-843, 1998.

Richter, A., Wittrock, F., Eisinger, M., and Burrows, J. P.: GOME observations of tropospheric BrO in Northern Hemispheric spring and summer 1997, Geophys. Res. Lett., 25, $2683-$ 2686, 1998.

Schroeder, W. H., Anlauf, K. G., Barrie, L. A., Lu, J. Y., Steffen, A., Schneeberger, D. R., and Berg, T.: Arctic springtime depletion of mercury, Nature, 394, 331-332, 1998. 